\title{
The Effect of Recessions on the Relationship Between Output Variability and Growth*
}

\author{
Ólan T. Henry and Nilss Olekalns \\ Department of Economics \\ The University of Melbourne \\ Parkville \\ Victoria 3052
}

May 19, 2000

\begin{abstract}
This paper investigates the relationship between output volatility and growth using post-war real GDP data for the United States. We expand on recent research by Beaudry and Koop (1993) documenting the asymmetric effect of recessions on output growth. The results presented in this paper suggest that output volatility is highest when the economy is contracting. While we find that the economy expands most rapidly following a recession, this expansion is offset by the negative impact of output uncertainty.
\end{abstract}

*The authors thank Michelle Barnes and participants at the Fifth Annual Australasian Macroeconomics Workshop for their comments on an earlier draft of this paper. Any errors in the paper are our responsbility. 


\section{Introduction}

In this paper, we investigate the role that recessions play in affecting the dynamics of real output growth. We extend the idea, first found in Beaudry and Koop (1993), that the "current depth of recession" (hereafter CDR) produces an asymmetry in output growth. This asymmetry is reflected in what is sometimes known as a "bounce-back" effect, namely that output growth recovers strongly following a recent recession.

Previous analyses of the CDR effect have neglected other recent evidence regarding the dynamics underlying output, which suggests that output volatility acts to retard output growth (Beaudry and Koop 1993, Bodman and Crosby 1998, Jansen and Oh 1999). In turn, the papers establishing a link between output volatility and growth have ignored the possibility of asymmetric output adjustment. (Woodford 1990, Kormendi and Meguire 1985, Grier and Tullock 1989, Caporale and McKiernam 1996, Speight 1999). Nor have these papers considered the possibility that output variability itself may be subject to asymmetries.

Our paper brings these previously disparate strands of the literature together. We consider a CDR-GARCH-M time series representation for United States' output growth. This specification enables an investigation of CDR asymmetries in the data whilst allowing for the possibility of a negative volatility effect on output and for that volatility to be also subject to an asymmetry.

The results strongly support the CDR-GARCH-M specification. We find that the economy tends to expand fastest in the period immediately after a 
recession. However, this expansion is offset by the negative effects of output uncertainty; we find that the estimated conditional variance of output is highest in the periods following a negative innovation to growth and that this acts to dampen growth.

The paper is organised as follows. In section 2, we describe the CDRGARCH-M methodology. The results are presented in section 3 and section 4 concludes the paper.

\section{Methodology}

Our starting point is the standard ARMA representation of output growth

$$
\Theta(L) \Delta y_{t}=\mu+\Phi(L) \varepsilon_{t},
$$

where $\Delta$ is the first difference operator, $y_{t}$ is a measure of the natural logarithm of real output, $\mu$ is a term capturing any drift in growth, $\varepsilon_{t}$ is an iid error term, and $\Theta(L)$ and $\Phi(L)$ are polynomials in the lag operator $L$. Equation (1) can be used to forecast the effect of an innovation on output out to some time horizon $j$ according to $\sum_{i=1}^{j} \psi_{i} \varepsilon_{t}$, where

$$
\Psi(L)=\frac{\Phi(L)}{\Theta(L)}=\sum_{i=0}^{\infty} \psi_{i} L^{i} .
$$

These forecasts will be conditional on there being a symmetric output response to positive and negative innovations. However, measures of shock persistence derived from (1) and forecasts derived from (2) will be biased if the data are not fully consistent with the symmetry assumption. 
One way of relaxing the symmetry constraint is to follow Beaudry and Koop (1993) and augment (1) with a measure of the "current depth of recession" $(C D R)$. This is defined as the gap between the current level of output and its historical maximum level, that is, $C D R_{t}=\max \left\{y_{t-s}\right\}_{s=0}^{t}-y_{t} . C D R$ will take non-zero values either when output dips below its trend value due to a negative shock or in the aftermath of a positive shock as output returns to trend. The implication of adding the $C D R$ term to (1) is that the conditional expectation of future output is influenced by whether the current level of output is above, below or at its historical maximum.

With the introduction of the $C D R$ term, equation (1) is modified according to

$$
\Theta(L) \Delta y_{t}=\mu+\{\Psi(L)-1\} C D R_{t}+\Phi(L) \varepsilon_{t},
$$

where the lag polynomial $\Theta(L)$ is of order $p, \Phi(L)$ is of order $q$, and $\Psi(L)$ is of order $r$ with $\Psi(0)=1$. This parameterisation for $\Delta y_{t}$ is very simple and nests the ARMA model (1) while allowing for the possibility of asymmetries associated with different stages of the business cycle.

Beaudry and Koop (1993) fit (3) to United States real GNP data over the period 1947:1 to 1989:4 and find that it performs better than a linear autoregressive model. Further, they construct impulse response functions and conclude that innovations to GNP are more persistent in expansions than in recessions. Jansen and Oh (1999) also find that (3) outperforms a smooth transition regression model when fitted to a measure of industrial production. ${ }^{1}$

\footnotetext{
${ }^{1}$ Bradley and Jansen (1997) extend Beaudry and Koop's (1993) model to the other G7
} 
Our concern in this paper is not just to identify an asymmetry in output growth but to determine whether output volatility affects growth once asymmetries are accounted for. Therefore, we model the conditional variance of output and the conditional mean using a modified GARCH-M specification. Conventional GARCH models allow for both 'volatility clustering' (i.e., the tendency for periods of high (low) volatility to follow periods of high (low) volatility and for the conditional variance to affect the conditional mean (Engle 1982, Bollerslev 1986, Engle, Lilien and Robins 1987). However, unlike conventional GARCH models, we generalise the conditional mean and conditional variance to allow for the possibility that they are affected by the state of the business cycle. This leads to the following CDR-GARCH-M model,

$$
\begin{aligned}
& \Theta(L) \Delta y_{t} \quad= \mu+\{\Psi(L)-1\} C D R_{t}+\lambda \sqrt{h_{t}}+\Phi(L) \varepsilon_{t} \\
& \varepsilon_{t} \sim N\left(0, h_{t}\right) \\
& h_{t}=\varpi+\alpha(L) h_{t-1}+\beta(L) \varepsilon_{t-1}^{2}+\gamma(L) I_{t-1} \varepsilon_{t-1}^{2} \\
& \text { where } \quad I_{t}=1 \text { if }\left\{\max \left\{y_{t-s}\right\}_{s=0}^{t}-y_{t}\right\}>0 \\
& \quad I_{t}=0 \text { otherwise }
\end{aligned}
$$

where the persistence of shocks to the conditional mean and to the conditional variance can vary according to the phase of the business cycle. In essence the model proposes a threshold in the variance. Periods where the $C D R$ term is non-zero, will lead to higher variance of output compared with periods where the $C D R$ term is zero, if the coefficient $\gamma$ is statistically significant. This model is an extension of the Threshold GARCH of Glosten, Jagannathan and countries and find that it performs well relative to linear specifications. 
Runkle (1993).

\section{Results}

The data used are United States real GNP measured in billions of chained (1992) dollars, originally sourced from Bureau of Economic Analysis and reformatted by Economic Information Systems. The data are quarterly and span the period 1947:1 to 1998:4. The upper panel of Figure 1 plots the quarterly growth rate in the data while the lower panel plots the CDR variable.

Table 1 reports maximum likelihood estimates of (3) using the scheme proposed by Campbell and Mankiw (1987) to determine the order of the lag poly-

nomials, $p, q$, and $r$. This involves setting the maximum values of $p, q$, and $r$ to 3 and $p+q+r=6$. The optimal model for each number of parameters was chosen using the Akaike (1974) and Schwarz (1978) information criteria.

The results in Table 1 are broadly consistent with those reported by Beaudry and Koop (1993), namely that growth is higher in periods following recessions. Moreover it is not possible to exclude the CDR term from (3) on statistical grounds.

Given that the aim of this study is to examine the volatility of output over the business cycle we move to the CDR-GARCH_M model discussed above. Table 2 reports the maximum likelihood estimates of the model obtained using the quasi-maximum likelihood approach of Bollerslev and Wooldridge (1992). The lag order in the conditional mean equation was determined initially by assuming $p=q=r=3$ and testing down. The preferred model was an 
$\operatorname{ARMA}(2,2) p=q=2$, with one lag of the CDR term, $r=1$, and a GARCH in mean coefficient $\lambda$.

The results of a Ljung-Box test on the standardised residuals, $Q(4)$, suggest that the preferred model is free from serial correlation in the mean equation. Furthermore the choice of a Threshold GARCH $(1,1)$ parameterisation for the conditional variance equation appears appropriate. We also evaluate the adequacy of the GARCH specification by using Pagan and Sabau's (1992) moment based test. This test has its basis in the implication derived from a GARCH model that $E\left(\varepsilon_{t}^{2}\right)=h_{t}$. The test is based upon the satisfaction of the restriction $H_{0}: \delta_{0}=0, \delta_{1}=1$ in the auxiliary regression $\varepsilon_{t}^{2}=\delta_{0}+\delta_{1} h_{t}+v_{t}$, where $v_{t}$ represents a white noise innovation. As reported in Table 2, the estimated CDR-GARCH model satisfies the moment condition at all usual levels of significance. Moreover, on the basis of a Ljung-Box test for serial correlation in the squared, standardised residuals, $Q^{2}(4)$, we are unable to detect evidence of mis-specification in the conditional variance.

The CDR-GARCH-M model collapses to a CDR model under the restrictions $\lambda=\alpha=\beta=\gamma=0$. However the restrictions are overwhelmingly rejected using a Wald test. The test statistic is 43.1249 , which under a $\chi^{2}(4)$ distribution indicates that the marginal significance of the test is 0.0000. The CDR-GARCH-M model appears to offer a superior conditional data characterisation to the standard CDR model of Beaudry and Koop (1993). The positive and significant coefficient associated with $C D R_{t-1}$ in the conditional mean equation indicates the asymmetry in economic growth, that is, growth is fastest in the recovery 
phase of a recession. The model also displays evidence of an asymmetric volatility response to innovations in the growth rate. That is, periods where the $C D R$ term is non-zero lead to higher levels of output volatility than periods where the $C D R$ term is zero. This suggests that periods where output has fallen below its historical maximum are inherently more volatile than booms.

This asymmetry in volatility is clearly depicted in figures 2 and 3 . These figures show the news impact curves, depicting the relationship between innovations to growth and the volatility of output, holding information constant at time $t-1$ and before. ${ }^{2}$ The equation for the $G A R C H(1,1)$ news impact curve is $h_{t}=A+\beta \varepsilon_{t-1}^{2}$, where $A=\omega+\alpha h_{t-1}$. In our model, the news impact curve during non-recessionary periods, i.e., when $C D R_{t}=0$, is $h_{t}=A+\beta \varepsilon_{t-1}^{2}$ In recessionary periods, i.e., when $C D R_{t}>0$, the news impact curve is $h_{t}=A+(\beta+\gamma) \varepsilon_{t-1}^{2} \cdot{ }^{3}$

The simulated news impact curve in figure 2 is consistent with the absence of a relationship between news about growth and the volatility of output during non-recessionary periods. Conversely, in recessionary periods, the significance of the $\gamma$ parameter results in large innovations in growth being associated with large values of $h_{t}$. The significant and negative coefficient on the GARCH in mean term points towards a negative volatility feedback on growth. The news impact curve confirms that this feedback will be strongest after a period of

\footnotetext{
${ }^{2}$ Because the $\operatorname{GARCH}(1,1)$ is formulated in the squares of $\varepsilon_{t}$ positive and negative shocks are treated in the same way. The relationship between $\varepsilon_{t}^{2}$ and $h_{t}$ is known as the news impact curve.

"Our use of the terms "recession" and "non-recession" differs from their normal usage. For exposition, we will restrict the use of the term "recession" to mean a period in which $C D R_{t}>0$.
} 
recession. In effect recessions result in increased output uncertainty which in turn serves to retard recovery following unfavourable news about output.

These conclusions are all dependent on the model we have selected being an adequate representation of the data generating process. The Ljung-Box and Pagan-Sabau tests reported above suggest our model specification is appropriate. However there is the potential for bias due to asymmetric response to the sign or magnitude of the innovation, $\varepsilon_{t}$, or to bias associated with periods where the CDR term is non-zero.

To identify potential misspecification of the conditional variance due to asymmetric response to innovations in growth, $\varepsilon_{t}$, we calculated Engle and Ng's (1993) test for size and sign bias in conditionally heteroskedastic models. Define $S_{t-1}^{-}$as an indicator dummy that takes the value of 1 if $\varepsilon_{t-1}<0$ and the value zero otherwise. The test for sign bias is based on the significance of $\phi_{1}$ in

$$
\varepsilon_{t}^{2}=\phi_{0}+\phi_{1} S_{t-1}^{-}+v_{t}
$$

where $v_{t}$ is a white noise error term. If positive and negative innovations in $\varepsilon_{t}$ impact on the conditional variance of growth differently to the prediction of the model, then $\phi_{1}$ will be statistically significant. It may also be the case that the source of the bias is caused not only by the sign, but also the magnitude of the shock. The negative size bias test is based on the significance of the slope coefficient $\phi_{1}$ in

$$
\varepsilon_{t}^{2}=\phi_{0}+\phi_{1} S_{t-1}^{-} \varepsilon_{t-1}+v_{t}
$$

Likewise, defining $S_{t-1}^{+}=1-S_{t-1}^{-}$, then the Engle and $\mathrm{Ng}$ (1993) joint test for 
asymmetry in variance is based on the regression

$$
\varepsilon_{t}^{2}=\phi_{0}+\phi_{1} S_{t-1}^{-}+\phi_{2} S_{t-1}^{-} \varepsilon_{t-1}+\phi_{3} S_{t-1}^{+} \varepsilon_{t-1}+v_{t}
$$

where $v_{t}$ is a white noise disturbance term. Significance of the parameter $\phi_{1}$ indicates the presence of sign bias. That is, positive and negative realisations of $\varepsilon_{t}$ affect future volatility differently to the prediction of the model. Similarly significance of $\phi_{2}$ or $\phi_{3}$ would suggest size bias, where not only the sign, but also the magnitude of innovation in growth is important. A joint test for sign and size bias, based upon the Lagrange Multiplier Principle, may be performed as $T . R^{2}$ from the estimation of (7). The results in table 2 suggest the model is free from size and sign bias.

Finally, we test for bias in the conditional variance arising from the failure to adequately capture the effects of recessions. Again this test may be performed using an LM approach based upon the auxiliary regression

$$
\varepsilon_{t}^{2}=\phi_{0}+\phi_{1} I_{t-1}+\phi_{2} C D R_{t-1}+v_{t}
$$

where $I_{t}=1$ if $\left\{\max \left\{y_{t-s}\right\}_{s=0}^{t}-y_{t}\right\}>0$ and is zero otherwise. In other words, $I_{t}$ captures periods when the economy is "in recession". The CDR term is used to capture biases due to the depth of the recession. The test is based upon the restrictions $\phi_{1}=0, \phi_{2}=0$ and is distributed as a $\chi^{2}(2)$. The test statistic of 1.9836, indicates a marginal significance level of 0.3709. There is no evidence of bias due to recessions in the model. 


\section{Conclusion}

In common with the results of Beaudry and Koop (1993), Bradley and Jansen (1997) and Jansen and Oh (1999) the evidence in this paper suggests that U.S.A. economic growth differs according to whether the economy's level of output has fallen relative to its historical maximum. However we demonstrate that the CDR-GARCH-M model provides a superior conditional characterisation for US post war GNP to the standard CDR model. This indicates that the volatility of U.S. economic growth is also affected by the level of output relative to the historical maximum; contractionary periods tend to be more volatile than expansions of similar magnitude. The CDR-GARCH-M model passes a battery of standard specification tests as well as a series of $L M$ tests designed to detect bias due to size and sign of innovation and bias due to recessions.

Our results provide further support for the view that there exists a significant asymmetry in the United State's growth rate, with growth accelerating as the economy recovers from recessions. However, we also document an increase in output volatility that accompanies recessions and which acts to dampen subsequent growth. Research is proceeding to see if these findings also occur for other countries. 
Table 1 Parameter Estimates - CDR models

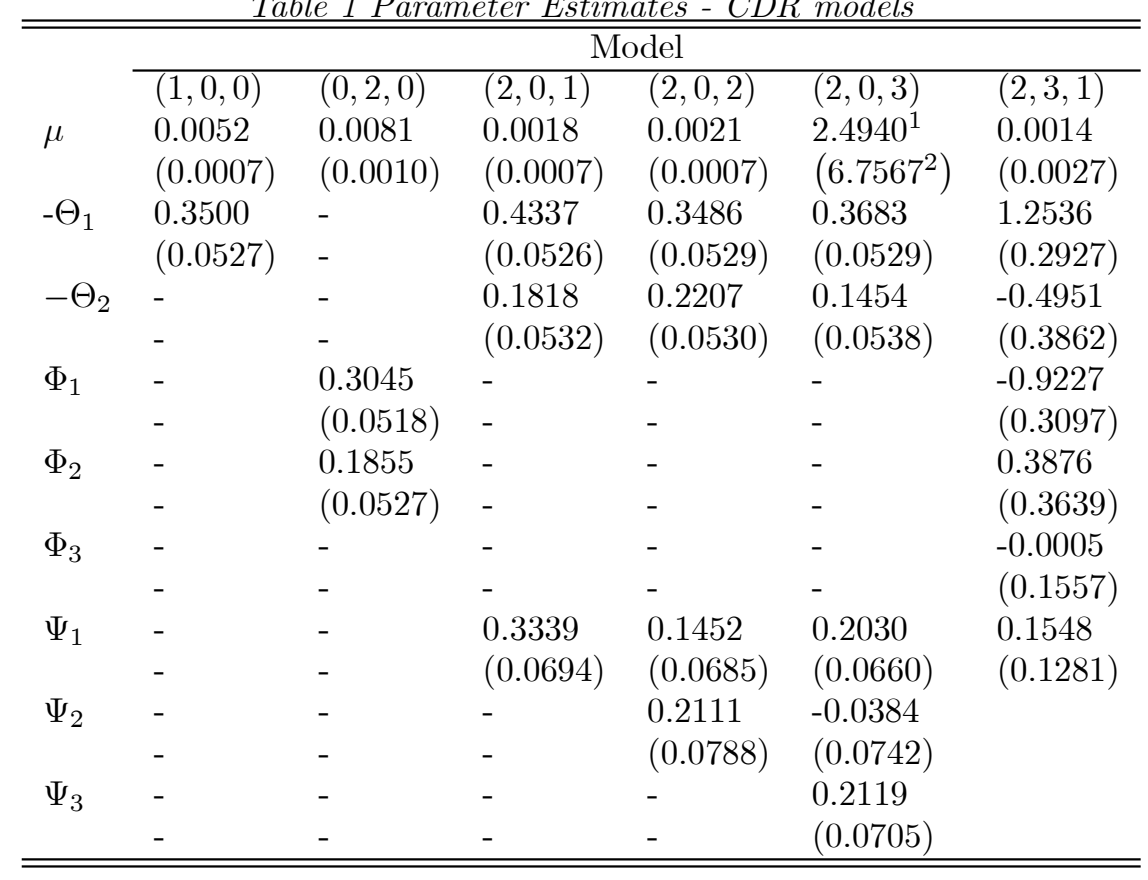

Notes to table 1: Standard errors displayed as (.). ${ }^{1} \times 10 e^{-32} \times 10 e^{-4}$ 
Estimates of the $C D R-G A R C H(1,1)-M$ Model

\begin{tabular}{lllllll}
\hline \hline$\mu$ & $-\Theta_{1}$ & $-\Theta_{2}$ & $\Psi_{1}$ & $\lambda$ & $\Phi_{1}$ & $\Phi_{2}$ \\
\hline 0.0048 & 0.5898 & -0.0243 & 0.2032 & -0.2430 & -0.1094 & 0.1157 \\
$(0.0010)$ & $(0.0943)$ & $(0.0943)$ & $(0.0646)$ & $(0.1078)$ & $(0.1068)$ & $(0.0756)$ \\
& & & & & & \\
\hline \hline$\omega$ & $\alpha$ & $\beta$ & $\gamma$ & $\mathrm{L}$ & & \\
\hline 0.00003 & 0.5030 & 0.0086 & 0.4958 & 853.0649 & & \\
$(0.00001)$ & $(0.1102)$ & $(0.0664)$ & $(0.1978)$ & & & \\
\hline
\end{tabular}

\begin{tabular}{llllll}
\hline \hline$Q(4)$ & $Q^{2}(4)$ & $P-S$ & N-Sign & N-Size & Joint \\
\hline 0.7800 & 5.6853 & 2.6835 & -0.3228 & 0.5906 & 0.8082 \\
{$[0.9411]$} & {$[0.2239]$} & {$[0.2674]$} & {$[0.7472]$} & {$[[0.5555]$} & {$[0.8475]$} \\
\hline \hline
\end{tabular}

Standard errors displayed as (.). Marginal significance levels displayed as

$[\cdot]$ 


\section{References}

[1] Akaike, H. 1974. "A New Look at Statistical Model Identification", IEEE Transactions an Automatic Control, AC-19, 716-723.

[2] Beaudry, P. and G. Koop. 1993. "Do Recessions Permanently Chnage Output?" Journal of Monetary Economics, 31. 149-63.

[3] Bodman, P.M. and M. Crosby. 1998. "The Australian Business Cycle: Joe Palooka or Dead Cat Bounce." University of Melbourme, Department of Economics Working Paper \# 586.

[4] Bollerslev, T. 1986. "Generalised Autoregressive Heteroscedasticity," Journal of Econometrics, 31, 307-27.

[5] Bollerslev, T., and Wooldridge, J.M. 1992. "Quasi-Maximum Likelihood Estimation and Inference in Models with Time Varying Covariances", Econometric Reviews, 11, 143-72.

[6] Bradley, M.D. and D.W. Jansen. 1997. "Nonlinear Business Cycle Dynamics: Cross-Country Evidence on the Persistence of Aggregate Shocks," Economic Inquiry, 35, 495-509.

[7] Campbell, J.Y. and Mankiw, N.G. 1987. Are Output Fluctuations Transitory?, Quarterly Journal of Economics, 102, 857-880.

[8] Caporale, T. and B. McKiernan. 1996. "The Relationship Between Output Volatility and Growth: Evidence from Post War UK Data." Scottish Journal of Political Economy, 43(2), May, 229-236. 
[9] Engle, R.F. 1982. "Autoregressive Conditional Heteroscedasticity with Estimates of the Variance of United Kingdom Inflation." Econometrica, 50, 987-1007.

[10] Engle, R.F., D.M. Lilien and R.P. Robins. 1987. "Estimating Time Varying Risk Premia in the Term Structure: The Arch-M Model," Econometrica; 55(2), March, 391-407.

[11] Engle, R.F. and Ng, V. 1993 "Measuring and Testing the Impact of News on Volatility", Journal of Finance, 48, 1749-1778.

[12] Glosten, L.R., Jagannathan, R. and Runkle, D. 1993. "On the Relation Between the Expected Value and the Volatility of the Nominal Excess Return on Stocks", Journal of Finance, 48, 1779-1801.

[13] Grier, K. and G. Tullock. 1989. "An Empirical Analysis of Cross-National Economic Growth, 1951-1980." Journal of Monetary Economics, 24, 25976.

[14] Jansen, D.W. and W. Oh. 1999. "Modelling Nonlinearity of Business Cycles: Choosing Between the CDR and STAR Models." Review of Economics and Statistics, 81(2), May, 344-49.

[15] Kormendi, R. and P. Meguire. 1985. "Macroeconomic Determinants of Growth: Cross-Country Evidence." Journal of Monetary Economics, 16, $141-63$. 
[16] Mullineux, A., D.G. Dickinson and W. Peng. 1993. Business Cycles. Blackwell, Oxford.

[17] Pagan, A. and Sabau, H. 1992. "Consistency Tests for Heteroscedasticity and Risk Models", Estudios Economicos, 7, 3-30.

[18] Speight, A.E.H. 1999. "UK Output Variability and Growth: Some Further Evidence." Scottish Journal of Political Economy, 46(2), May, 175-184.

[19] Schwarz, G. 1978. "Estimating the Dimension of a Model," The Annals of Statistics, 6, 461-464.

[20] Woodford, M. 1990. "Learning to Believe in Sunspots." Econometrica, 58, $277-307$. 

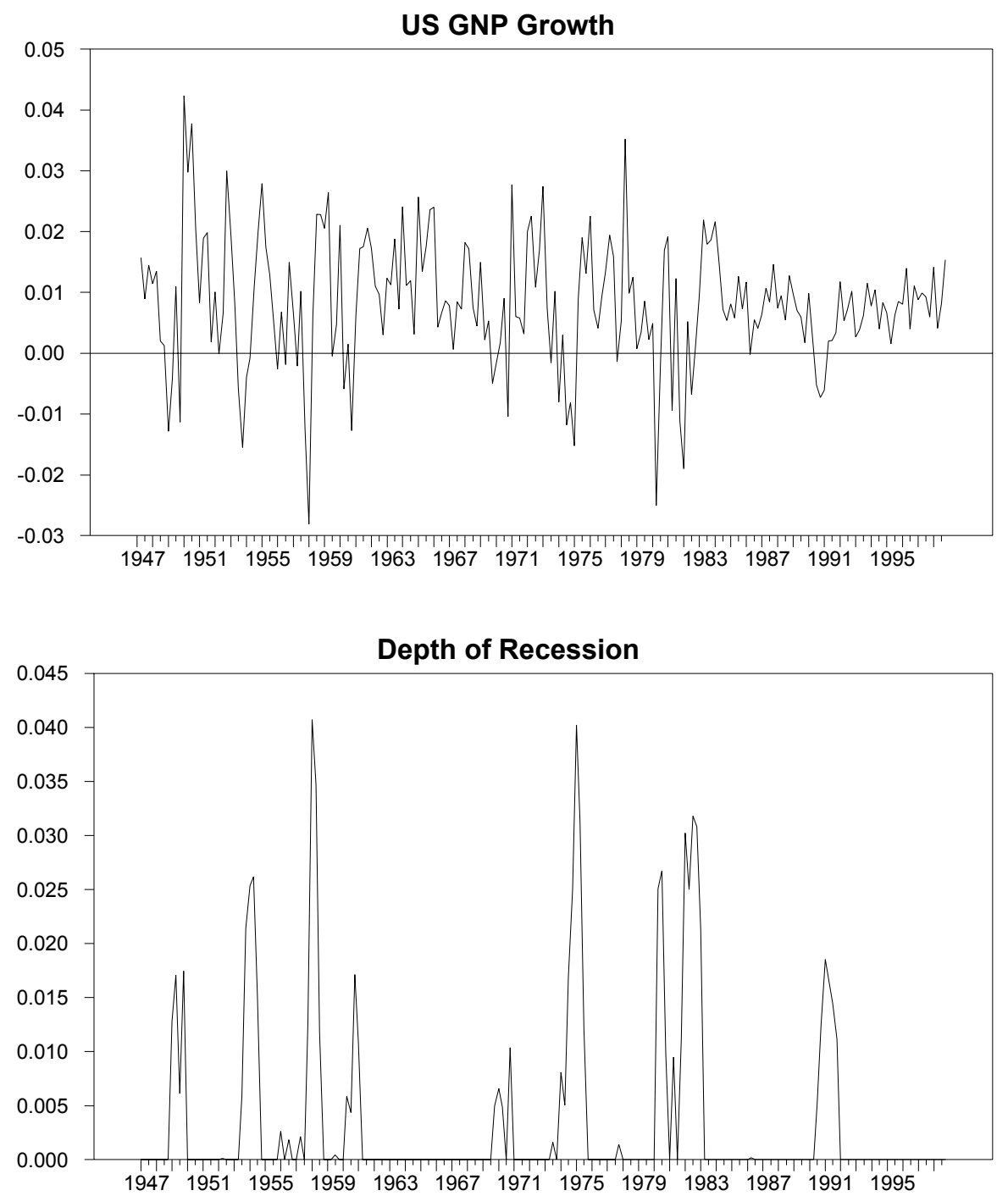

Figure 1: The Data 


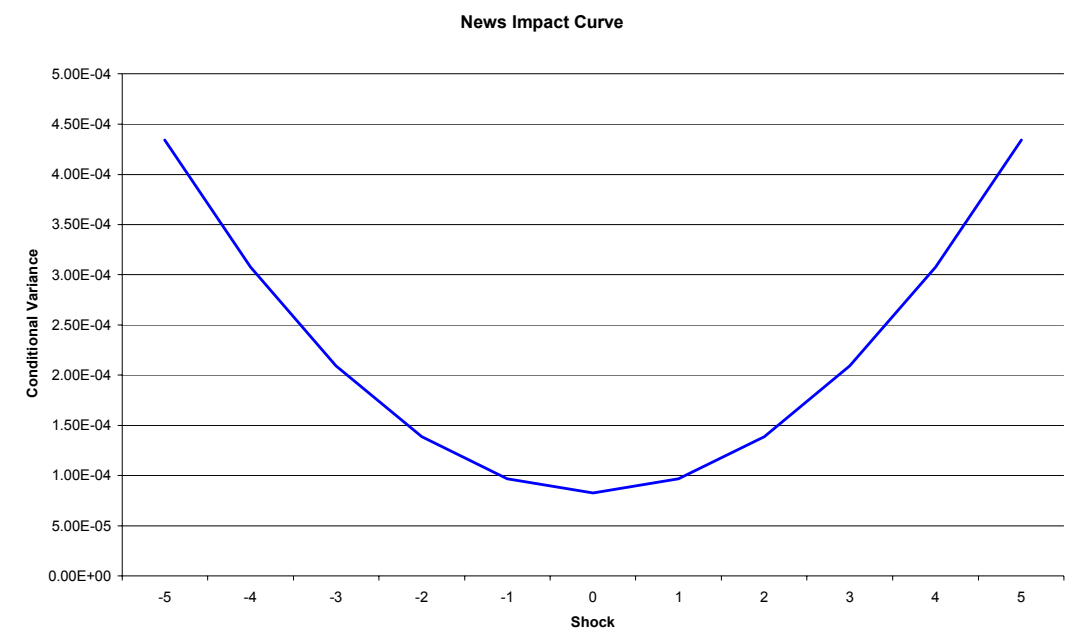

Figure 2: Innovations to Growth and Output Variability

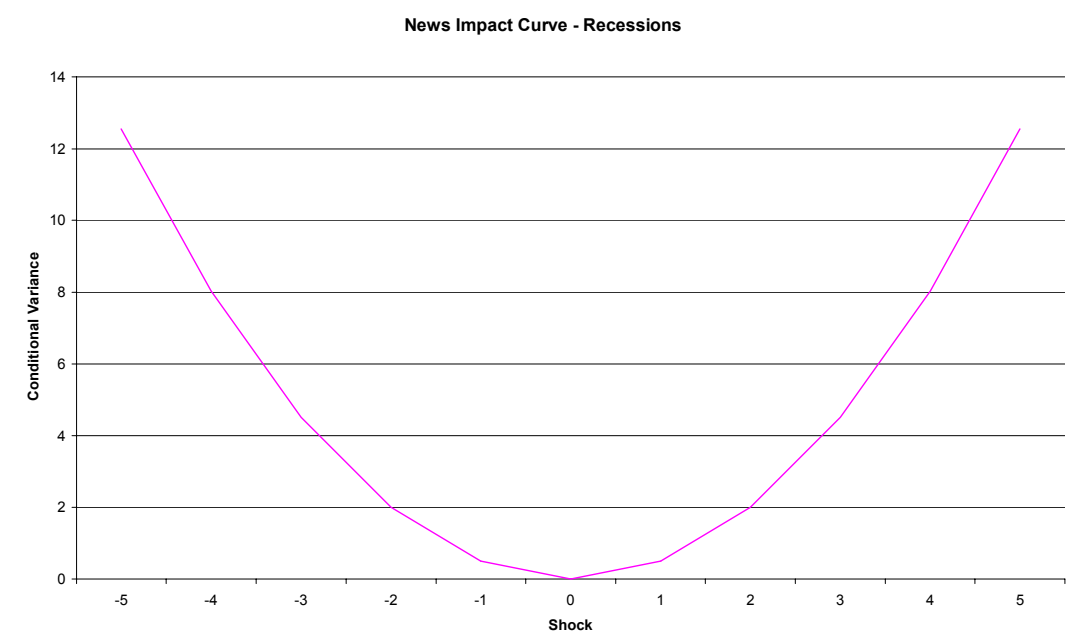

Figure 3: Innovations to Growth and Output Variability - Recessions 